First Peoples Child \& Family Review

An Interdisciplinary Journal Honouring the Voices, Perspectives, and Knowledges of

First Peoples through Research, Critical Analyses, Stories, Standpoints and Media

Reviews

\title{
First Nations Children Count: Enveloping Quantitative Research in an Indigenous Envelope
}

\section{Cindy Blackstock}

Volume 4, Number 2, 2009

URI: https://id.erudit.org/iderudit/1069337ar

DOI: https://doi.org/10.7202/1069337ar

See table of contents

Publisher(s)

First Nations Child and Family Caring Society of Canada

\section{ISSN}

1708-489X (print)

2293-6610 (digital)

Explore this journal

Cite this article

Blackstock, C. (2009). First Nations Children Count: Enveloping Quantitative Research in an Indigenous Envelope. First Peoples Child \& Family Review, 4(2), 135-143. https://doi.org/10.7202/1069337ar
Article abstract

Indigenous peoples repeatedly call for disaggregated data describing their experience to inform socio-economic and political policy and practice change (United Nations Permanent Forum on Indigenous Issues, 2003; UNICEF, 2003; Rae \& the Sub Group on Indigenous Children and Youth, 2006). Although there has been significant discourse on the destructive historical role of western research with Indigenous communities (RCAP, 1996; Smith, 1999; Schnarch, 2004) and more recently on cultural adaptation of qualitative research methods (Smith, 1999; Bennet, 2004; Kovach, 2007), there has been very little discussion on how to envelope western quantitative social science research within Indigenous ways of knowing and being. This paper begins by outlining the broad goals of Indigenous research before focusing on how quantitative research is used, and represented, in the translation of Indigenous realities in child health and child welfare. Given the rich diversity of Indigenous peoples and their knowledges, this paper is only capable of what respected Indigenous academic Margo Greenwood (2007) would term 'touching the mountaintops' of complex and sacred ideas.
This document is protected by copyright law. Use of the services of Érudit (including reproduction) is subject to its terms and conditions, which can be viewed online.

https://apropos.erudit.org/en/users/policy-on-use/ 


\title{
First Nations Children Count: Enveloping Quantitative Research in an Indigenous Envelope
}

\author{
Cindy Blackstock ${ }^{\mathrm{a}}$
}

a Ph.D., Executive Director, First Nations Child and Family Caring Society, Ottawa, ON, Canada.

Indigenous peoples repeatedly call for disaggregated data describing their experience to inform socio-economic and political, policy and practice change (United Nations Permanent Forum on Indigenous Issues, 2003; UNICEF, 2003; Rae \& the Sub Group on Indigenous Children and Youth, 2006). Although there has been significant discourse on the destructive historical role of western research with Indigenous communities (RCAP, 1996; Smith, 1999; Schnarch, 2004) and more recently on cultural adaptation of qualitative research methods (Smith, 1999; Bennett, 2004; Kovach, 2007), there has been very little discussion on how to envelope western quantitative social science research within Indigenous ways of knowing and being. This paper begins by outlining the broad goals of Indigenous research before focusing on how quantitative research is used, and represented, in the translation of Indigenous realities in child health and child welfare. Given the rich diversity of Indigenous peoples and their knowledges, this paper is only capable of what respected Indigenous academic Margo Greenwood (2007) would term "touching the mountaintops' of complex and sacred ideas.

\section{Cutting Edge Quantitative Research: lapping at the shorelines of Indigenous knowledge}

Some researchers believe that qualitative methods are, almost inherently, more "indigenous" in nature than quantitative methods. Such assumptions are often based on a belief that Indigenous peoples were (and are) more concerned about storytelling and ceremony than

Questions or correspondence concerning this article may be addressed to:

cblackst@fncaringsociety.com

\begin{abstract}
Indigenous peoples repeatedly call for disaggregated data describing their experience to inform socio-economic and political policy and practice change (United Nations Permanent Forum on Indigenous Issues, 2003; UNICEF, 2003; Rae \& the Sub Group on Indigenous Children and Youth, 2006). Although there has been significant discourse on the destructive historical role of western research with Indigenous communities (RCAP, 1996; Smith, 1999; Schnarch, 2004) and more recently on cultural adaptation of qualitative research methods (Smith, 1999; Bennett, 2004; Kovach, 2007), there has been very little discussion on how to envelope western quantitative social science research within Indigenous ways of knowing and being. This paper begins by outlining the broad goals of Indigenous research before focusing on how quantitative research is used, and represented, in the translation of Indigenous realities in child health and child welfare. Given the rich diversity of Indigenous peoples and their knowledges, this paper is only capable of what respected Indigenous academic Margo Greenwood (2007) would term 'touching the mountaintops' of complex and sacred ideas.
\end{abstract}

scientific and numeric endeavour. However, as Nobel Prize nominee, Dr. Ervin Laszlo (2007) posits, many of the most celebrated advances in western science are now just lapping at the shorelines of the complex knowledge held in trust by Indigenous peoples for millennia. For example, Laszlo (2007) describes how the Indigenous beliefs in an interconnected reality across time and space are now being confirmed by the most advanced theories in physics such theories as String Theory and the Theory of Everything. In addition, quantum level physics is starting to bare out the importance of acting and thinking in what Aboriginal people call "a good way" or with "a good mind. Research appears to confirm what Indigenous peoples have believed for millenniathat information shapes reality instead of being a by product of reality (Laszlo, 2007). Laszlo is not alone in his assessment of how advanced Indigenous scientific 


\section{Acknowledgements:}

Special thanks to the National Collaborating Centre on Aboriginal Health who made this paper possible.

knowledge is. Nobel Prize winning biologist, Dr George Wald joins Peter Knutson and David Suzuki in arguing that advanced genetic science is now confirming the long held Indigenous belief that all life forms are genetically interconnected (Knutson and Suzuki, 1992).

These recent developments build on a long history of Indigenous science informing western science, particularly in fields of pharmacology, medicine, agriculture and architecture (Weatherford, 1988; RCAP, 1996). For example, an impressive $60 \%$ of the world's food source is derived from the knowledges of Indigenous peoples in the Americas (Weatherford, 1988).

From a mathematical perspective, numbers were developed to represent the natural world. As Indigenous peoples have long defined their cultures and languages in reference to the natural world, numbers are often not a foreign concept. For example, Meso American cultures invented zero in about $32 \mathrm{BC}$ - centuries before it was "discovered" in India. Meso-American cultures had also developed the most accurate calendar (365 days per year) and had perfected architectural development in ways that outstripped civilized European society (Mann, 2006.) Although Indigenous scientific and numeric concepts varied, and were shaped differently than western systems, it is clear that these differences did not handicap Indigenous scientific enlightenment. Given that Indigenous peoples do have sophisticated systems of thought that produce scientific information, the widely held belief that quantitative research is somehow more culturally foreign than qualitative research is suspect.

I suggest that qualitative and quantitative research methods are equally appropriate for use with Indigenous peoples so long as they are appropriately enveloped in Indigenous knowledge and research protocols. However, it has been my experience that quantitative research is much more persuasive to western policy makers and thus is often a preferred option when pursuing the research translation agenda. The problem is that even though quantitative research is often more convincing to western policy makers they often expect Indigenous peoples' research to be qualitative which puts Indigenous peoples in a "catch 22 ". If Indigenous researchers employ qualitative methods only, they may not get the policy impact they need but if they use quantitative methods the research can be perceived by non Indigenous policy makers as not being indigenous enough. This is why it is so essential to debunk the myth that quantitative research is somehow more or less Indigenous than qualitative methods. This reality, coupled with the fact that Indigenous communities the world over are calling for quality disaggregated data describing their situation (United Nations Permanent Forum on Indigenous Issues, 2003; UNICEF, 2003; Rae \& the Sub Group on Indigenous Children and Youth, 2007), suggests an acute need for a robust discussion on how to "indigenize" quantitative research methods.

\section{Quantitative Translation Research}

Although western universities and democratic societies say they welcome alternative ways of knowing the world, the reality is that the dominant power structures still heavily privilege western paradigms. What this means, in practical terms for Indigenous peoples, is that they often have to "confirm" their knowledge and reality using western methods before non Aboriginal policy makers and funding bodies will listen. This reality is what drives the translation research goal in Indigenous research. Translation does not imply a manipulation of the data. It simply means employing western research tools to explore and document what, quite frankly, most Indigenous people believe is an obvious reality. For example, First Nations have been reporting for decades that the child welfare system was removing a disproportionate number of First Nations children (Assembly of First Nations, 1993; RCAP, 1996) but without western research "evidence" these claims were often minimized (Blackstock, 2003). Once the Canadian Incidence Study on Reported Child Abuse and Neglect (Trocmé et. al, 2001) produced quantitative evidence supporting First Nations claims, the over representation of First Nations children in child welfare care was more seriously considered by non-Aboriginal child welfare authorities.

The focus on research as a translation tool is an important distinction from the western research doctrine of viewing research as a tool to generate "new knowledge." Research as translation, as opposed to being solely innovative, is one example wherein the interfaces between Indigenous and non Indigenous knowledge can create tension and confusion for non Indigenous researchers. The highest professional accolades, and funding sources, in western academia are reserved for those who produce new knowledge. By comparison, Indigenous peoples believe that the most important things about humanity are already known and thus the highest standard is the wisdom held by the Elders who 
have studied ancestral knowledge for a lifetime (Auger, 2001.) What this means, in practical terms, is that western academics often get little reward for conducting translation-based research, research that is precisely so often needed by Indigenous peoples. The end result is that, until recently, there have been very few non Indigenous social science researchers who were willing to engage in translation based research. Consequently, many Indigenous researchers struggled to achieve two, often mutually exclusive goals (being recognized in western academia and doing meaningful translation research) so that Indigenous communities could access the policy change and resources they needed.

Although the value of translation based research is beginning to be recognized in western academic circles, practical barriers such as funding and academic recognition continue to persist. Eliminating these barriers is critical for Indigenous communities who, increasingly, are calling for more translation based research in order to get the "evidence" and funding needed to redress the longstanding socio-economic challenges they face.

Quantitative research is most frequently sought out by Indigenous peoples wanting to pursue specific policy goals requiring some sort of western approval or support (United Nations Permanent Forum on Indigenous Issues, 2003; UNICEF, 2003; Rae \& the Sub Group on Indigenous Children and Youth, 2007). The question of whether this should or should not be the case is another debate. Indigenous peoples often face grave socioeconomic conditions requiring immediate relief. In order to get that relief, they need to present the most compelling and convincing case to western policy makers using quantitative research. This often means presenting the case using quantitative research. In order to perform the translation function well, quantitative researchers need to thoroughly understand the research goal, build respectful relationships with the respective Indigenous community and adapt their research methods to more closely reflect the Indigenous context.

\section{Preparing the Envelope: Adapting Western Research Methods for the Translation Re- search Purpose}

Non Indigenous researchers must understand how western research was used as a colonial tool within and towards Indigenous communities and peoples (RCAP, 1996; Smith, 1999; Bamblett, 2005). These colonial research paradigms resulted in knowledge extraction from, as oppose to knowledge benefit for, Indigenous peoples. As a result, Indigenous peoples have developed a healthy scepticism of western research, insisting that researchers demonstrate how the research will result in community benefit and how Indigenous knowledge and ethical protocols will be respected (Schnarch, 2004). Observance of Indigenous ethical standards and values are not discretionary nor should researchers believe that western research ethics reviews accomplish the same goal rendering a secondary Indigenous ethics process redundant. Adherence to Indigenous ethical standards should be thought of as an essential pre-requisite to effective research. These ethical standards are often not onerous and serve to enhance both the quality and utility of results.

Inherent to the ethics of Indigenous research protocols is a requirement that researchers will nurture and maintain a respectful relationship with the Indigenous peoples who are subject to the study. This respect unfolds throughout the research endeavour, beginning with the formation of the research question. As a default setting, Indigenous communities should develop the research question in partnership with the researcher (Blackstock, 2003) because the whole goal of translation based research is to evidence a community reality. Indigenous communities should also be consulted in development of research methodology in order to ensure the inclusion of relevant information, the proper observance of cultural or contextual protocols and the proper interpretation and dissemination of findings (Schnarch, 2004).

Western researchers have often been raised on the idea that distance equals objectivity and frequently raise concerns about whether or not the formation of relationships within a translation-based research context introduces unnecessary bias. Porter (1995) argues that western conflation of relational distance and scientific objectivity is a falsehood in that it fails to recognize other sources of bias sourced in the researcher, method and unaccounted variables. This view has gained traction in the social science research community, notably with the growing popularity of Participatory Action Research and the generally accepted practice of declaring sources of bias in research articles. Indigenous peoples do not try to deny the influence of relationship or personal interest on research. They believe that centering community values and interests, whilst maintaining a proper balance of research interests and emotions, ensures research integrity and efficacy (Smith, 1999).

Given the diversity of Indigenous communities, it is critical that researchers work with Indigenous community leaders to identify the most effective and respectful ways of conducting and disseminating research. Useful guides to these discussions are the Ownership, Control, Access and Possession (OCAP) research principles (Schnarch, 2004) and the Reconciliation in Child Welfare: Touchstones of Hope for Indigenous Children, Youth and Families principles (Blackstock, Cross, Brown, George 
\& Formsma, 2006). Both these documents were jointly developed by Indigenous and non Indigenous child welfare experts to maximize the efficacy of child welfare research, policy and practice respecting Indigenous children and families.

\section{The Holistic Worldview: setting the stage for putting quantitative research in an Indig- enous envelope}

The widely held Indigenous holistic world view holds that we are part of an interconnected reality created by everything that came before us. This foundation of experience and knowledge often called oral history shapes our current and future realities. Optimal functioning of this complex system, including all human experience and endeavours, is achieved when there is balance between the spiritual, emotion, physical and cognitive dimensions.

The holistic model is broadly held by Indigenous peoples worldwide but it can be expressed differently. One of the most broadly used expressions of the holistic model is the Medicine Wheel:
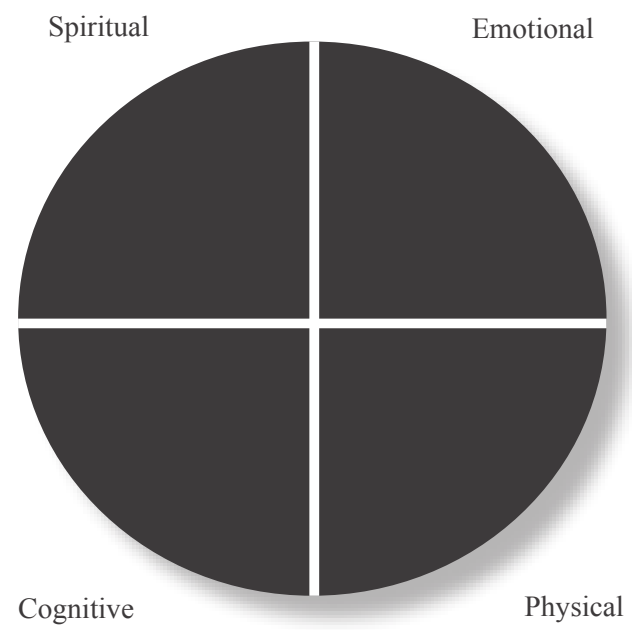

Applied in a research context, clarity of thought is achieved when the research reaches spiritual, emotional, cognitive and physical balance. The holistic worldview acknowledges that periods of imbalance are inevitable during the research process. The goal, therefore, is to identify these periods of imbalance and act in a way that achieves cumulative balance over the course of the research project.

\section{Quantitative research in an Indigenous envelope}

What would quantitative research look like when enveloped within an holistic approach? The following section describes how Indigenous researchers or non Indigenous researchers advised by Indigenous peoples have enveloped quantitative research in an Indigenous holistic world view envelope by invoking the spiritual, physical, emotional and cognitive dimensions of being.

\section{Invoking the spiritual}

For Indigenous peoples, spirituality plays a key role in contextualizing knowledge. Protecting knowledge, and its sacred status, results in instilling deference to the collective and is anchored in community values such as the Seven Grandfather Teachings: wisdom, truth, humility, honesty, bravery, love, and generosity (Auger, 2001). The spiritual has supernatural and natural dimensions, creating a reality wherein myth and reality become mutually reinforcing. For example, environmentalists Knudtson and Suzuki (1992) describe how Indigenous beliefs in circular creation, often termed reincarnation in western contexts, contributes to effective natural resource management. This belief system holds that animals, plants and other necessities of human life will only recreate themselves if they are treated with great respect by the current generation of humans. A failure to do so results in these essential life resources not being available for future generations and the eventual extinction of the human race. First Nations have known for centuries what the Al Gore is just finding out - if you do not treat the earth with respect then you are treating yourself badly (Auger, 2001).

From a quantitative social science research perspective, Indigenous research reports consistently employ symbolic art, legends and teachings to add meaning and context to the findings. For example, a young Yorta Yorta woman named Kahlit Luttrell designed the magnificent cover of the Secretariat National Aboriginal and Islander Child Care [SNAICC] (2002) report entitled through black young eyes. The image is intended to capture the emotions that children living with violence experience. Poetry and traditional teachings are threaded throughout the report alongside qualitative and quantitative research findings in order to add meaning. The back cover of the report was considered equally important and features the following poem by Lorraine Patten:

They think I don't know

What about me?

Does anyone care? 
The fights, the blues and the despair-

Some people think

I don't know

But the feeling inside me

Tells me what's so

"I'm sorry, I'm sorry

They say back and forth

But what about me?

I wish I could talk

SNAICC, 2002

Similarly, the First Nations Child and Family Caring Society includes symbolism in its report entitled Wen:de: We are Coming to the Light of Day. The cover of the report features a First Nations girl holding a candle looking to the future and the inside of the cover features images of light. Interestingly Michelle Nahanee, the very talented First Nations designer who compiled the report, had visions of light and, at the same time, Elder Donald Horne was thinking of naming the report Wen: de which means "coming to the light of day". The name and the design were spiritually inspired and this spirit enveloped the dedication of the report made in memory of a First Nations boy named Jordan who unnecessarily spent over two years in a hospital as governments fought over payment for his at-home-care (Lavallee, 2005). The back cover of the report featured an inspirational quote encouraging the reader to move the report recommendations into a lived experience for First Nations children. These two reports were independently produced thousands of miles away by Indigenous peoples and yet they are remarkably similar in terms of how spirituality is expressed.

In contrast, western social work and health journals require articles to be submitted in text form only and the inclusion of spiritual content is typically discouraged. In general, the more bland the cover of the journal, the more scholarly it appears to a western audience. Is it any wonder why the readership of academic journals is so limited? Western research has not yet embraced the spiritual as a legitimate and integral aspect of knowledge -but Indigenous researchers are demonstrating how spirituality can help readers infuse information with meaning to create and internalize knowledge.

\section{Invoking the emotional}

For some reason, the trend in western research is to conflate objective truth with an absence of emotion and passion. It seems the more indifferent you are about a topic the more respected you are for your "objective" and "unbiased" opinion (Priddy, 1999). As Theodore
Porter (1995) notes, however, western researchers cannot excise their interests and emotions from pure science research let alone the social sciences centered on human experience. Linguistic science affirms Porter's point of view, noting that people interpret information, including research, through cognitive frames which are shaped by our life experience, culture and context (Lakoff, 2004). Neuroscience has found evidence suggesting that emotion and cognition are linked (Rabins, 2003) and thus true research emotional objectivity in western science is more myth than reality.

For millennia, Indigenous peoples believed that such distance between logic and emotion is impossible, not to mention undesirable. Consistent with a holistic world view, Indigenous peoples believed that a balance of cognition, emotion, spirituality and physical knowing created the optimal climate to cultivate valid and useful knowledge (RCAP, 1996). It is important to understand the importance of the word "balance" in the holistic worldview. Indigenous peoples and non Indigenous researchers would agree that too much emotion distorts reality. However, Indigenous peoples believe that balance, from an emotional point of view, means acknowledging and embracing emotion as a reality versus trying to sideline it or deny it (Kovach, 2007). This means going beyond "declaring bias" in a research report to understanding your emotional connection to reality as a dynamic resource and influence throughout the research process.

\section{Invoking the physical}

The Wen:de: We are Coming to the Light of Day report (Blackstock, C., Prakash, T., Loxley, J., and Wien, F., 2005) was printed with ecologically friendly ink on paper that protected old growth forests. The report needed to embody the values of respect for the land that are so integral to the healthy development of Indigenous children.

Indigenous languages are used in many quantitative research reports respecting Indigenous peoples such as the Our children: Nos enfants report authored by the Nunavik Regional Health Board of Health and Social Services (2003.) The cover features an Inuksuk embedded with pictures of children from Nunavik and the Inuktitut language is used for the title and throughout the body of the report. The statistical reports that typify quantitative research appear in this report, but they are interpreted in Inuktitut.

For indigenous peoples the written word is frozen when knowledge was meant to be alive. To infuse life into the written word, the physical elements of an Indigenous quantitative report must be in balance with the emotional, spiritual and cognitive elements. 


\section{Invoking the cognitive}

The cognitive domain is very familiar to western researchers: it is also highly valued by Indigenous peoples, although it is important to keep in mind that there are two very different worldviews informing cognition at work here. Indigenous peoples are more likely to value ancestral knowledge, interconnection and value the influence of the emotional, physical and spiritual domains on cognition than western researchers (Blackstock, 2007.)

The use of a common language (i.e.: French or English) can create an illusion of common understanding between western researchers and Indigenous communities. For example, the words "partnership" and "consultation" are often used by Canadian federal and provincial governments to describe how they work with Indigenous peoples but Indigenous peoples often have a far different interpretation both of what these words mean and how they are actualized by government officials. Western governments often believe that partnership with Indigenous peoples has been achieved whereas Indigenous peoples often believe it is still being aspired to (RCAP, 1996; MacDonald, 1999.) Research ethics in western research are not necessarily reflective of the personal ethics of the researcher but, in Indigenous cultures, no such differentiation exists - ethics are something you are, not something you put on (Blackstock, 2007).

Researchers involved in translation research need to become fluent and multilingual in both Indigenous and non Indigenous constructs of knowledge in order to accurately describe and translate the situation of Indigenous peoples for western policy makers. Western researchers must, in effect, walk in multiple worlds. In practice, researchers will often get invaluable assistance from Indigenous peoples who have long had to function in "multiple worlds," one of which (a Euro-colonial world) has actively marginalized Indigenous ways of knowing and being.

\section{Comparing First Nations and western repre- sentations of a quantitative study}

The Canadian Incidence Study on Reported Child Abuse and Neglect [CIS] (Trocmé et. al., 2001) provides an excellent contrast of how a population based study appears when it is enveloped in western and First Nations ways of knowing and being. The western report summarizes the major Canadian findings whereas the First Nations report, Mesnmimk Wasatek, presents the secondary analysis of First Nations data (Trocmé, MacLaurin, Fallon, Knoke, Pitman \& McCormack, 2006.) The CIS is widely respected by Aboriginal and non Aboriginal child welfare researchers alike. First Nations have found the CIS data especially useful as it is the first national child maltreatment study to specifically collect disaggregated data on the experiences of First Nations children and their families. The inclusion of First Nations in the CIS study necessitated some minor methodical modifications, such as respecting community ethics review processes and working with First Nations experts to develop and prioritize research questions for secondary data analysis: the results, however, are that much the richer on account of these slight methodological modifications.

Table 2 shows how the final report contrasts with the First Nations report across several key areas. The one area where the reports do not differ is in terms of the rigor and quality of the data analysis and the presentation of findings.

In my view, the CIS is one of the most successful examples of how quantitative research can be placed and employed within an Indigenous envelope. The openness of the CIS research team to work respectfully with First Nations researchers and communities to envelope the CIS in Indigenous ways of knowing and being, while taking seriously the translation research function, has resulted in significant policy advancements. For example, the First Nations CIS report has informed a national First Nations child welfare funding policy, amendments to provincial and First Nations child welfare programs and policy submissions to the United Nations.

Although the research team still feels improvements could be made to future cycles of the CIS to further maximize its policy efficacy, it serves as an excellent example of how quantitative research can support the Indigenous translation research purpose.

\section{Indigenous Research - on its own terms}

Indigenous scholar Margaret Kovach (2007) argues that only Indigenous research centered on Indigenous ontology and methods is truly Indigenous - everything else is a compromise. I agree. I am encouraged by the growing numbers of Indigenous studies that validate Indigenous knowledge on its own terms and provide a framework for Indigenous knowledge and research to inform western social science.

In general, western social sciences have lagged behind the western pure sciences in terms of recognizing Indigenous knowledge and appreciating its potential to inform western knowledge. Social work and health theories still tend to understand the world in segmented scope (e.g... structural theory, ecological theory, complexity theory, systems theory, phenomenology) or in segmented populations (i.e.: feminism, ethnic studies and anti oppressive frameworks) (Blackstock, 2007). Although some western research methods such 


\begin{tabular}{|c|c|c|}
\hline Content & Western CIS & First Nations CIS \\
\hline Cover & 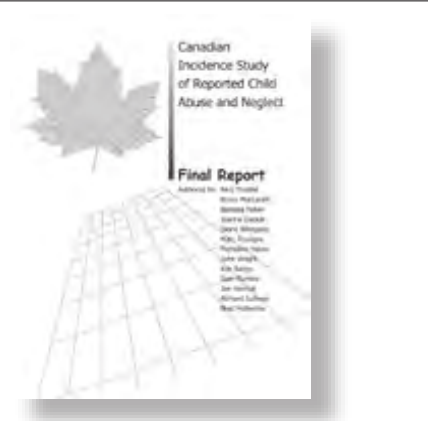 & (4) \\
\hline Cover Meaning & $\begin{array}{l}\text { Government designed with a } \\
\text { maple leaf likely symbolizing } \\
\text { Canada and a grid but no meaning } \\
\text { is noted in the report }\end{array}$ & $\begin{array}{l}\text { Designed by a First Nations author } \\
\text { who was commissioned by the } \\
\text { Mi'kmaw First Nation who named } \\
\text { the report. }\end{array}$ \\
\hline Title & $\begin{array}{l}\text { Canadian Incidence Study of } \\
\text { Reported Child Abuse and Neglect }\end{array}$ & $\begin{array}{l}\text { Mesnmick Wasatek: Catching a Drop } \\
\text { of Light }\end{array}$ \\
\hline Meaning of Title & None Noted & $\begin{array}{l}\text { Named gifted by the Mi'kmaw } \\
\text { Family and Children's Services. "The } \\
\text { tears of the beautiful child in the } \\
\text { artwork fall into the sacred smudge } \\
\text { bowl filled with water, the essence of } \\
\text { all life. The butterfly symbolizes how } \\
\text { the CIS information helped shape the } \\
\text { transformation of services offered } \\
\text { by Mi'kmaw Family and Children's } \\
\text { Services to better support Mi'kmaw } \\
\text { children and families. }\end{array}$ \\
\hline $\begin{array}{l}\text { Internal Photos/ } \\
\text { Images }\end{array}$ & None & Portions of the cover art throughout \\
\hline $\begin{array}{l}\text { Methodology } \\
\text { Group }\end{array}$ & Quantitative & Quantitative \\
\hline
\end{tabular}

Table 2: Comparing the Mainstream and First Nations CIS Report layouts

as ethnography explore phenomena across time, these approaches tend to focus on specific events or groups instead of an interconnected reality. Social work has not even begun to seriously consider something along the lines of the Theory of Everything that is being contemplated in physics in recognition of emerging evidence of the interrelationship of all things (Laszlo, 2007).

The pure sciences have gone full circle from discounting Indigenous knowledge in favour of myopic scientific knowledge and then, having followed the trail laid by years of scientific endeavour, are lapping at the shorelines of Indigenous knowledge again. In contrast, social science adheres to a myopic and dated concept of western science that largely discounts the validity of Indigenous knowledge. As a result, western social sciences often cast Indigenous knowledge to elective status or bracket it as only having relevance to Indigenous peoples. This diminishes the value of Indigenous knowledge and also limits western social science knowledge and research.

The potential for the social sciences to benefit from Indigenous knowledge is exponential. Indigenous peoples have been living in social, economic and political systems in North America for at least 20,000 years and have highly sophisticated methods of surveying and transmitting knowledge across long periods of time. This knowledge could assist social scientists in expanding the potential of longitudinal research approaches and gleaning important ancestral knowledge about human existence and relationships. Many of the problems that western science has found most elusive such as global warming, dealing with cultural difference, and resolving conflict can be significantly enlightened by respectfully embracing Indigenous knowledge. Physics, biology, ecology, pharmacology and others have already benefited from Indigenous knowledge (Weatherford, 1988) and now it is time for social sciences to do the same thing before they get left too far behind.

\section{Summary}

Indigenous peoples and their knowledge count. Not just for Indigenous peoples but for everyone. Understanding the different purposes of Indigenous research provides a framework for Indigenous and non Indigenous research to co-exist respecting the distinctiveness and validity of their knowledges and research methods.

Enveloping quantitative research in an Indigenous envelope does not "water it down" but rather 


\section{First Nation Children Count}

contextualizes the information and provides more knowledge pathways (emotional, spiritual, and physical) than the typical western approach. After all, when you look at Table 2 what report would you, regardless of your culture, rather read? The western one with the grid and maple leaf or the one with beautiful child and the smudge bowl. Western social science has a lot to learn from Indigenous peoples - it is time for it to reach out to the Elders and go to school.

\section{References}

Assembly of First Nations (1993). Reclaiming our nationhood; strengthening our heritage: report to the Royal Commission on Aboriginal Peoples. Ottawa: Assembly of First Nations.

Auger, D. (2001). The northern Ojibwe and their family law. Doctoral dissertation submitted to Osgood Hall Law School, York University. North York: York University.

Bamblett, M. (2005). From welfare to wellbeing: progress in pursuing the well being of Aboriginal and Torres Strait Islander Children in Australia. In First Nations Child and Family Caring Society of Canada (Ed.) Joining hands across the world for Indigenous children. Ottawa: First Nations Child and Family Caring Society of Canada.

Bennett, M. (2004). A review of the literature on the benefits and drawbacks of participatory action research as a research method. First Peoples Child and Family Review, 1(1), 19-33.

Blackstock, C. (2003). First Nations child and family services: Restoring peace and harmony in First Nations communities. In Child Welfare: Connecting Research Policy and Practice edited by Kathleen Kufeldt and Brad McKenzie (Eds.) (pp. 331-343). Waterloo: Wilfred Laurier University Press.

Blackstock, C. (2007). The breath of life and the embodiment of life: Indigenous knowledge and western research. Submitted to the World Indigenous Peoples Journal on Education.

Blackstock, C., Cross, T., Brown, I., George, J. \& Formsma, J. (2006). Reconciliation in Child Welfare: Touchstones of Hope for Indigenous Children, Youth and Families. Ottawa: First Nations Child and Family Caring Society of Canada.

Blackstock, C., Prakash, T., Loxley, J., \& Wien, F. (2005). Wen: de: we are coming to the light of day. Ottawa: First Nations Child and Family Caring Society of Canada.

Greenwood, M. (2007). Personal conversation. July 26, 2007.
Kovach, M. (2007). Searching for arrowheads: An inquiry into Indigenous approaches using a tribal methodology with a Nehyiyaw Kiskeyihtamotiwin worldview. Doctoral dissertation. University of Victoria.

Knudtson, P. \& Suzuki, D. (1992) Wisdom of the Elders: native and scientific ways of knowing about nature. Vancouver: Greystone publishing.

Lakoff, G. (2004). Don't think of an elephant: know your values and frame the debate. White River Junction: Chelsea Green Publishing.

Lavallee, T. (2005). Honouring Jordan: Putting First nations children first and funding fights second. Paediatrics and Child Health, Vol. 10, Number 9, 527-529.

Laszlo, E. (2007). Science and the Akashic field. Rochester: Inner Traditions.

MacDonald, K. (1999). First Nations Summit Child Welfare Committee Discussion Paper: Phase One Prepared for the First Nations Summit Child Welfare Committee and the Ministry for Children and Families, October 31, 1999.

Mann, C. (2006). 1491: New revelations of the Americas before Columbus. New York: Vintage Books.

Nunavik Regional Board of Health and Social Services (2003). Our children/nos enfants. Kuujjuaq: Nunavik Regional Board of Health and Social Services.

Porter, T. (1995). Trust in numbers: the pursuit of objectivity in science and public life. Princeton: Princeton University Press.

Priddy, R. (1999). Scientific objectivity in question. Retrieved 24 August 2007at http://home.no.net/rrpriddy/lim/5.html.

Rabins, P. (2003). Cognitive neuroscience of emotion. American Journal of Psychiatry, Volume 160, 193-194.

Rae, J. \& the Sub Group on Indigenous Children and Youth (2006). Rights and reality: a report on indigenous children and the United Nations convention on the rights of the child. Ottawa: First Nations Child and Family Caring Society of Canada.

Royal Commission on Aboriginal Peoples [RCAP] (1996). The report on the Royal Commission on Aboriginal Peoples. Available on line at http://www.ainc-inac.gc.ca/ch/rcap/rpt/ $\underline{\mathrm{k} \text { e.html } 1996 .}$

Schnarch, B. (2004). Ownership, control, access and possession or self determination applied to research. Ottawa: National Aboriginal Health Organization. 


\section{First Peoples Child \& Family Review, Volume 4, Number 2, 2009}

Smith, L. (1999). Decolonizing methodologies; research and Indigenous peoples. London: Zed Books Limited.

SNAICC (2002). Through young black eyes: a handbook to protect Indigenous children from the impact of family violence and child abuse. North Fitzroy, Australia: SNAICC.

Trocmé, N., MacLaurin, B., Fallon, B. Daciuk, J. Billingsley, D., Tourigny, M., Mayer, M., Wright, J., Barter, K., Burford, G., Hornick, J., Sullivan, R., \& McKenzie, B. (2001). Canadian incidence study of reported child abuse and neglect: final report. Ottawa, ON: Health Canada.

Trocme, N., MacLaurin, B., Fallon, B., Knoke, D., Pitman,L., \& McCormack, M. (2006). Mesnnmimk Wasatek: catching a drop of light: understanding the over-representation of First Nations children in Canada's child welfare system: An analysis of the Canadian Incidence Study of Reported Child Abuse and Neglect (CIS-2003). Ottawa: First Nations Child and Family Caring Society of Canada.

United Nations Children's Fund (UNICEF) (2003). Innocenti Digest No.11: Ensuring the Rights of Indigenous Children. Florence: Innocenti Research Centre \& UNICEF.

United Nations Permanent Forum on Indigenous Issues (2003). Chairpersons summary of the high level panel and dialogue on Indigenous children and youth. New York: United Nations Economic and Social Council.

Weatherford, J. (1988). Indian givers: how the Indians of the Americas transformed the world. New York: Crown Publishers. 